\title{
A ANTROPOLOGIA FORENSE NA DIAGNOSE SEXUAL
}

\section{ARTIGO ORIGINAL}

TIMOTEO, Andrey Luís Mauá ${ }^{1}$

BONIN, Juliana Galliani ${ }^{2}$

RIBEIRO, Maira Pinheiro ${ }^{3}$

SOUZA, Paula Helena dos Santos e ${ }^{4}$

MENEGUETTE, Cicero ${ }^{5}$

TIMOTEO, Andrey Luís Mauá. Et al. A Antropologia Forense na Diagnose Sexual. Revista Científica Multidisciplinar Núcleo do Conhecimento. Ano 03, Ed. 07, Vol. 07, pp. 31-41, Julho de 2018. ISSN:2448-0959, Link de acesso: https://www.nucleodoconhecimento.com.br/saude/antropologia-forense

\section{RESUMO}

A Antropologia Forense se dedica à identificação humana em casos de desastres em massa, área criminal e investigações arqueológicas, sendo de extrema relevância

\footnotetext{
${ }^{1}$ Graduando em Medicina pela Universidade Brasil - Fernandópolis, Brasil. Graduado em Biomedicina pela Unicesumar - Maringá, Brasil.

${ }^{2}$ Graduanda em Medicina pela Universidade Brasil - Fernandópolis, Brasil.

${ }^{3}$ Graduanda em Medicina pela Universidade Brasil - Fernandópolis, Brasil.

${ }^{4}$ Graduanda em Medicina pela Universidade Brasil - Fernandópolis, Brasil.

${ }^{5}$ Doutor pela Faculdade de Medicina de São José do Rio Preto, Brasil. Mestre pela Universidade Federal de Minas Gerais, Brasil. Título de Especialista em Medicina Legal pela Associação Médica Brasileira, Brasil. Graduado em Medicina pela Faculdade de Medicina de São José do Rio Preto, Brasil. Professor do Curso de Medicina da Universidade Brasil - Fernandópolis, Brasil.
} 
social, judicial e humanitária. O objetivo desse trabalho foi tecer uma breve descrição da aplicação da Antropologia Forense na Diagnose Sexual. Foi realizado um levantamento bibliográfico através da Biblioteca Virtual em Saúde. Para realizar a Diagnose Sexual são utilizados métodos morfológicos e métricos. Os resultados revelaram que dentre os elementos ósseos, o que possui maior dimorfismo sexual é o da bacia, seguido do crânio e ossos longos.

Palavras-chave: Antropologia Forense, Identificação Humana, Diagnose Sexual.

\section{INTRODUÇÃO}

A palavra Antropologia é derivada das palavras gregas "antropos" (humano ou homem) e "logos" (pensamento ou razão) (1).

Atualmente a Antropologia pode subdividir-se em três grandes campos de estudo: a Antropologia Física ou Biológica, que se centra no estudo dos componentes biológicos e genéticos do homem, ocupando-se do estudo de material colhido em escavações arqueológicas e em cenários de crimes e de desastres de massa, estando por isso relacionada com a anatomia, a arqueologia e as ciências forenses; a Antropologia Social, que se foca na explicação cultural do relacionamento familiar e da organização social e política das sociedades; e a Antropologia Cultural, que diversos autores consideram aglutinada com o campo de investigação antropológica anterior e que tem como alvo o estudo da ligação entre os sistemas simbólicos, as religiões e o comportamento humano e a análise da evolução dos seus costumes, crenças e manifestações artísticas ${ }^{(2)}$.

A Antropologia Forense é uma especialidade relativamente novo dentro da Medicina Legal que emprega os métodos da antropologia física e arqueologia para coleta e análise de evidências legais a partir de restos humanos, buscando estabelecer a identidade do sujeito através da individualização de características intrínsecas à situação ${ }^{(3,4)}$. Esta área do conhecimento iniciou-se no século 20 e vem sendo ampliada devido ao exponencial aumento da violência, pela necessidade do conhecimento da 
anatomia do esqueleto em ações jurídicas que envolvam a identificação e avaliação de restos humanos em decomposição ou esqueletizados ${ }^{(3)}$.

Segundo James e Nordby, o exame de restos humanos por antropologistas forenses deve ser focado em três tarefas: I) identificar a vítima ou pelo menos providenciar um perfil biológico, incluindo sexo, idade, estatura, ancestralidade, destreza manual, anomalias, patologias e características individuais; II) reconstruir o período postmortem baseado nas condições dos restos e a recuperação do contexto e III) fornecer dados sobre o evento da morte, incluindo evidência de trauma ocorrendo no período peri-mortem. É preciso uma equipe multidisciplinar (médicos, biólogos, cirurgiões dentistas, entre outros) para efetuar essas tarefas e, a partir delas, desenvolver um perfil biológico completo do indivíduo de tal maneira que se possa estreitar a variedade das possíveis identidades ${ }^{(5)}$.

A diagnose sexual, ou estimativa do gênero de uma vítima, baseia-se no dimorfismo sexual que se pode observar na espécie humana. O nível de exatidão da diagnose sexual é diretamente proporcional ao grau de dimorfismo sexual, ou seja, quanto maior for o grau de dimorfismo sexual da vítima, mais rigorosa será a estimativa sexual, o que acontece com o incremento da idade, uma vez que o dimorfismo sexual vai-se desenvolvendo com esta, até à fase adulta ${ }^{(6)}$.

Este trabalho tem o objetivo de tecer uma breve descrição da aplicação da Antropologia Forense na Diagnose Sexual.

\section{METODOLOGIA}

Para o levantamento bibliográfico foi utilizado o site da Biblioteca Virtual em Saúde (BVS) e pesquisado nas bases de dados Medical Literature Analysis and Retrieval System Online (MEDLINE), Literatura Latino-Americana (LILACS) e Scientific Electronic Libray Online (SciELO). Foram utilizados os descritores: Antropologia forense, Identificação humana e Diagnose sexual. 
Dentre as obras científicas selecionadas foram consideradas as escritas em português, espanhol e inglês, de acesso livre e disponível em texto completo.

\section{RESULTADOS E DISCUSSÃO}

\subsection{IDENTIFICAÇÃO HUMANA}

A preocupação de se identificarem indivíduos existe desde os primórdios das sociedades, apresentando um caráter humanitário e social muito importante e até imprescindível para que as consequentes medidas jurídicas relativas a um falecimento possam ser tomadas ${ }^{(7)}$.

A identidade de um indivíduo é o conjunto de características morfofisiológicas e psíquicas exclusivas dessa pessoa, sendo determinada por um processo objetivo, baseado em provas científicas. Ou seja, a identidade é o conjunto de características físicas, funcionais e, até, psíquicas, normais ou patológicas, que individualizam uma pessoa, diferenciando-a das demais ${ }^{(8)}$.

Os processos de identificação humana podem ser de dois tipos: comparativos ou reconstrutivos. A utilização de processos comparativos pressupõe a existência de elementos fiáveis estabelecidos ante mortem, como impressões digitais, radiografias, fichas médicas e dentárias, que serão confrontados com as características individualizantes da vítima, a fim de se chegar a uma identificação positiva. Os processos reconstrutivos utilizam-se quando não existem dados ante mortem disponíveis e apenas permitem esclarecer se um determinado indivíduo corresponde ou não a uma dada descrição, estabelecendo apenas uma identificação provável(9).

Os métodos de identificação são utilizados de acordo com o estado do corpo encontrado. Quando a identificação antropológica, odontologia legal e papiloscópica restaram insuficientes, o DNA passa a ser a última ferramenta para uma identificação definitiva e precisa ${ }^{(10)}$.

Os Institutos Médicos Legais (IML) são providos de profissionais na área de Antropologia Forense, para onde os cadáveres em situação de difícil identificação são 
encaminhados. É nessa fase que, através da atuação multidisciplinar de Médicos Legistas, Odonto-legais, farmacêuticos, químicos, biólogos, pode-se estimar o sexo, a estatura, determinação do grupo étnico ou a cor da pele do indivíduo a ser identificado, além de causa e tempo de morte(11).

\subsection{DIAGNOSE SEXUAL}

As células sexuais, ou gametas, são formadas nas gônadas (testículos e ovários) por um processo de divisão designado por meiose. Durante este processo de divisão celular, o número regular de cromossomos das células humanas - 46 - é reduzido para metade, para que cada célula tenha apenas 23 cromossomos - células haploides. A fusão das células sexuais, espermatozoide e óvulo, dá origem ao ovo, ou zigoto, que recebe 23 cromossomos de cada parte, totalizando os 46 cromossomos (célula diploide). Contudo, estes 46 cromossomos não são diferentes entre si. São, na verdade, 23 pares de cromossomos homólogos. Cada par de homólogos, com exceção dos cromossomos sexuais, é semelhante na forma e na constituição genética. Estes 22 pares de cromossomos homólogos designam-se autossômicos, e o par restante, cromossomos sexuais. Num indivíduo do sexo feminino, o $23^{\circ}$ par consiste em dois cromossomos $\mathrm{X}$ e num indivíduo do sexo masculino consiste num cromossomo $\mathrm{X}$ e num $\mathrm{Y}$. Estes dois cromossomos $(\mathrm{X}$ e $\mathrm{Y})$ são diferentes na forma $\mathrm{e}$ na constituição genética. Assim, cada óvulo feminino terá, na maioria dos casos, apenas um cromossomo $\mathrm{X}$ e, cada espermatozoide terá, ao acaso, ou um cromossomo $\mathrm{X}$ ou um $\mathrm{Y}$. E, é este acaso na constituição do espermatozoide que determina o sexo genético do ovo ou zigoto: a parte materna transmitirá sempre $X$, com as devidas exceções, e a masculina pode transmitir quer $X$ quer $Y$. Apesar dos indivíduos do sexo feminino, receberem dois cromossomos $X$, parece que apenas um desses cromossomos se mantém ativo. $\mathrm{O}$ outro cromossomo $\mathrm{X}$ forma um agregado de heterocromatina inativo e pode ser, frequentemente, observado como um pequeno ponto, designado corpúsculo de Barr. Ocorrida a fusão destas células sexuais, iniciasse o desenvolvimento do embrião(12,13).

A influência dos fatores genéticos e hormonais ocorre, alternadamente, nesta cadeia de eventos que definem as gônadas primárias, as estruturas sexuais internas e os 
órgãos sexuais externos. As identidades sexuais do cérebro e hipotálamo são adquiridas durante a vida pós-natal do indivíduo(14).

Podem ser três as causas principais que levam ao desenvolvimento de características distintas nos esqueletos dos dois sexos: a) a função reprodutora que se expressa fundamentalmente na variação morfológica da bacia; b) as diferentes influências genéticas no desenvolvimento dos ossos e nas suas proporções; c) as diferenças na quantidade e proporção de massa muscular, verificada pelas diferentes áreas de inserção muscular nos dois sexos. Todas estas causas agem em conjunto, conduzindo às diferenças fenotípicas do esqueleto que demarcam o sexo, pelo que não são separáveis nos seus efeitos ${ }^{(15-17)}$.

Os métodos mais utilizados e recomendados para a diagnose sexual são de dois tipos: os morfológicos e os métricos ${ }^{(18-20)}$. Os primeiros, qualitativos, baseiam-se na observação da morfologia de certos caracteres anatômicos, altamente dimórficos, de acordo com o seu enquadramento estrutural, classificando-os através de critérios descritivos, publicados, ao longo dos anos, por alguns autores conceituados ${ }^{(21-24)}$ do que é tipicamente feminino e tipicamente masculino. Os segundos, quantitativos, utilizam medições e referências anatômicas para, posteriormente, se aplicarem cálculos estatísticos como, por exemplo, as funções discriminantes ${ }^{(16,25,26,27)}$.

A existência de um esqueleto completo é a melhor situação para o diagnóstico do gênero de uma vítima, mesmo quando os restos humanos estão fragmentados, podese efetuar uma diagnose sexual com um elevado grau de precisão(28).

No esqueleto humano adulto, as áreas que, comprovadamente, exibem mais dimorfismo sexual são a bacia e o crânio, seguidos dos ossos longos e, por isso, fortemente, recomendadas por especialistas e muitos autores $^{(4,18,17,19,20,23,29,27,30,31,32,33,34,35,36)}$. Os restantes elementos do esqueleto exibem um grau de dimorfismo, geralmente, mais tênue, pelo que, a fiabilidade do diagnóstico sexual é menor $(37,38,39,40,41,42)$. 
Os dentes, frequentemente, se preservam melhor que outras partes do esqueleto, foram também alvo de muitos estudos. O dimorfismo sexual, neste caso, está mais bem representado nos caninos, mas os valores de eficácia de diagnose sexual, através da medição destes, encontram-se entre $75 \%$ e $80 \%$, o que é considerado pouco preciso ${ }^{(17)}$.

A participação da Medicina Dentária Forense nos processos de identificação humana conduz ao estabelecimento de critérios para a execução de estimativas do grupo étnico, do gênero, da idade à morte e da estatura de uma vítima de homicídio ou de desastre de massa, a serem aplicados num exame odontológico forense às arcadas dentárias e aos dentes ${ }^{(43)}$.

As técnicas de análise do DNA (ácido desoxirribonucleico) consolidaram-se como auxiliares e certificadoras dos exames antropológicos, pelo que o estudo do gene da amelogenina, que está presente em cromossomas recolhidos a nível pulpar, pela técnica PCR (Polymerase Chain Reaction), pode contribuir para a determinação do gênero de uma pessoa. Este gene da amelogenina, embora presente nos cromossomas $\mathrm{X}$ e $\mathrm{Y}$, apresenta um número de pares de bases $(\mathrm{pb})$ diferente, caso seja oriundo do cromossoma $X(212 \mathrm{pb})$ ou do $Y(228 \mathrm{pb})^{(44)}$.

\section{CONCLUSÃO}

Essa pesquisa proporcionou conhecimentos sobre a identificação humana e pontuou os melhores métodos de Diagnose Sexual amparada na Antropologia Forense.

No final desse trabalho é possível concluir que os ossos da bacia geram uma Diagnose Sexual mais precisa em relação aos ossos do crânio e os ossos longos. Nos casos em que o esqueleto não está adequadamente preservado, lança-se mão do exame odontológico forense para auxiliar no diagnóstico sexual, porém não possui a mesma eficácia dos ossos supracitados. As metodologias que utilizam a análise de DNA contribuem para a determinação sexual. 


\section{REFERÊNCIAS}

1-Marconi MA., Presotto ZMN. Antropologia - Uma introdução. São Paulo, Editora Atlas. $7^{a}$ edição, 2010.

2-Pereiro X. Apontamentos de Antropologia Sociocultural. Chaves, Universidade de Trás-os-Montes e Alto Douro, 2012.

3-Hercules HC. Medicina Legal. São Paulo: Atheneu; 2005.

4-Burns KR. Forensic anthropology training manual. Upper Saddle River: Prentice Hall, 1999.

5-James SH, Nordby JJ. Forensic science: an introduction to scientific and investigative techniques. Boca Raton: CRC Press; 2003.

6-Krenzer, U. Compendio de métodos antropológico-forenses para la reconstrucción del perfil osteo-biológico, Tomo II - Métodos para la determinación del sexo. Guatemala, Centro de Análisis Forense y Ciencias Aplicadas, 2006.

7-Paiva LAS, Rabelo APA. Identificação humana com a utilização de prótese total superior e de técnica de sobreposição de imagens. Saúde, Ética \& Justiça, 15(1), pp. 40-45, 2010.

8-Gomes AL, et al. A identificação humana de vítimas de desastres em massa: a importância e o papel da Odontologia Legal. Revista da Faculdade de Odontologia da UPF, v. 18, n. 2, pp. 224-229, 2013.

9-Silva SCP. A Contribuição da Perícia Odontológica na Identificação de Cadáveres. (Tese de Mestrado), 2007.

10-Pinheiro MF. Genética e biologia forense, e criminalística. In: Faculdade De Medicina Da Universidade Do Porto. Noções gerais sobre outras ciências forenses medicina legal. Porto, 2004. (Apostila). 
11-Oliveira RN, et al. Contribuição da odontologia legal a identificação post-mortem. Disponível em: <http://www.malthus.com.br/artigos_prints.asp?thus=s\&id=71>.

12-Campbell NA, Reece JB, Mitchell JG. Biology, 5th Edition, Benjamin/Cummings, EUA, 1999.

13-Fox SI. Human Physiology, 6th Edition, WCB/McGraw-Hill Companies, Inc., EUA, 1999.

14-Sizonenko PC. Human Sexual Differenciantion, in: Campana A, Dreifuss JJ, Sizonenko P, Vassalli JD, Villar J, Ares-Serono. Reproductive Health, Symposia Series - Frontiers in Endocrinology, Vol. 2. Ares Serono Symposia Publications, Roma, Itália, 1993.

15-Armelagos GJ, Van Gerven DP. Sexual dimorphism and human evolution: an overview. Hum. Evol. 9 (1980) 437-446.

16-Cunha E. Cálculo de funções discriminantes para a diagnose sexual do crânio. Provas de Aptidão Pedagógica e Capacidade Científica, Trabalho de síntese, Universidade de Coimbra, 1989.

17-White TD. Human Osteology, 2nd Edition, Academic Press, San Diego, EUA, 2000.

18-Bruzek J, Murail P. Methodology and reliability of sex diagnosis from the skeleton, in: in: A. Schmitt, E. Cunha, J. Pinheiro (Ed.) - Forensic Anthropology and Medicine: Complementary sciences from recovery to cause of death, Humana Press, Inc. New Jersey, 2006, pp. 225-242.

19-Rösing FW, Graw M, Marré B, Ritz-Timme S, Rothschild MA, Rötzscher K, Schmeling A, Schröder I, Geserisck G. Recommendations for forensic diagnosis of sex and age from skeleton. Homo 58-1 (2007) 75-89.

20-Ubelaker DH. Methodological considerations in the forensic applications of human skeletal biology, in: M. A. Katzenberg, S. Saunders, Biological anthropology of the human skeleton. Wiley-Liss, Wiley \& Sons, Inc., EUA, 2000. 
21-Bruzek J. A method for visual determination of sex, using the human hip bone. Am. J. Phys. Anthropol. 117-2 (2002) 157-68.

22-Buikstra JE, Ubelaker DH. Standards for data collection from human skeletal remains. Arkansas Archeological Survey Research series n44, EUA, 1994.

23-Ferembach D, Schwidetzky I, Stloukal M. Recommendation for age and sex diagnoses of skeletons. J. Hum. Evol. 9 (1980) 517-54

24-Phenice TW. A newly developed visual method of sexing the os pubis. Am. J. Phys. Anthrop. 30 (1969) 297-302

25-Cunha E, Van Vark G. The construction of sex discriminant functions from a large collection of skulls of known sex. Int. J. A 6-1 (1991) 53-66.

26-Giles E, Elliot O. Sex determination by function analysis of crania. Am. J. Phy. Anthrop. 21 (1963) 53-61

27-Krogman WM, İşcan MY. The Human Skeleton in Forensic Medicine, Charles C. Thomas, Springfield, II, EUA, 1986.

28-Galvão LCC. Determinação do sexo através da curva frontal e apófise mastoidea. (Tese de Doutoramento), 1998.

29-Byers SN. Introduction to Forensic Antropology - a texbook, 1st Edition, Allyn \& Bacon, EUA, 2001.

30-Cox M, Mays S. Human Osteology: In Archaeology and Forensic Science. Greenwich Medical Media Ltd, London, 2000.

31-Knight B, Saukko P. Knight's Forensic Pathology, 3 rd Edition, Edward Arnold Publishers Ltd, London, 2004.

32-Mendonça MC, Costa JP. Antropologia Forense, Arqui. 8-6 (1994) 405-412. 
33-Reichs KJ. Forensic osteology : advances in the identification of human remains, 2nd Edition, Charles C. Thomas Ltd Pub, Springfield, EUA, 1997.

34-Saunders SR, Katzenberg MA. Biological anthropology of the Human Skeleton, Wiley-Liss, a John Wiley \& Sons Inc., EUA, 2000.

35-Scheuer L, Black S. Osteology, in: T. Thompson, S. Black (Ed.) Forensic Human Identification, an introduction, CRC Press, Taylor \& Francis Group, EUA, 2007, pp.199219.

36-Simmons T, Haglund WD. Anthropology in a forensic context, in: Hunter J, Cox M. Forensic Archaeology, advances in theory and practice, Routledge, Taylor \& Francis Group, EUA, 2005, pp.159-176.

37-Asala SA. Sex determination from the head of the femur of South Africans whites and blacks. Forensic Sci. Int. 117(2001) 15-22.

38-Bidmos MA, Dayal MR. Further evidence to show population specificity of discriminant function equations for sex determination using talus of South Africans blacks. J. Forensic Sci. 49-6 (2004) 1165-1170.

39-Loth SR, Henneberg M. Mandibular Ramus Flexure: a new morphologic indicator of sexual dimorphism in the human skeleton. Am. Phys. Anthropol. 99 (1996) 473-485.

40-Purkait $\mathrm{R}$, \& Chandra H. A study of sexual variation in Indian femur. Forensic Sci. Int. 146 (2004) 25-33.

41-Wasterlain S, Cunha E. Comparative performance of femur and humerus epiphysis for sex diagnosis. Biom. Hum. et Anthropol. 18 (1-2) (2000) 9-13.

42-Zanella UP, Brown TM. Testing the validity of metacarpal use in sex assessment of human skeleton remains. J. Forensic Sci. 48-1(2003) 17-20.

43-Carvalho SPM, et al. A utilização de imagens na identificação humana em odontologia legal. Radiologia Brasileira, 42(2), pp. 125-130, 2009. 
44-Azevedo JMCA. A eficácia dos métodos de diagnose sexual em Antropologia Forense. (Tese de Mestrado),2008. 